\title{
How LIS professionals can use alerting services
}

Ina Fourie

Chandos: Oxford, 2006. I78p

ISBN I $84334128 \times$ (pbk.)

Price: unknown

This book focuses on the usefulness of alerting services for LIS professionals. It is a valuable and useful resource as it draws attention to the new and existing current awareness services which can be easily retrieved for updating ones information data banks. The availability of these services does not always mean that they are exploited for advancement of knowledge either by individuals or groups. This book provides a variety of definitions of current awareness services by several authors.

The book is divided into seven chapters, a detailed bibliography and an alphabetical index at the end. In the introductory chapter, the author explains about the need for alerting services and reasons why professionals must use these services. She describes how the challenges affect the professionals in their practice and how they can monitor such challenges through alerting services. For example, she says that there is a need for information professionals to understand their own information behaviour in order for them to make use of the alerting services to improve their knowledge generation.

In Chapter Two, the author explains the concepts of alerting services and the early development of current awareness services (CAS), and the rationale for offering these services. Chapter Three explains the relationship between the environment and the LIS professionals in practice, as well as LIS educators.

The variety of alerting services available for the benefit of LIS professionals are dealt with in the next chapter. The web site addresses provided can be used by novices for monitoring events, keeping track of trends and new research reports. Chapter Five describes in relative detail the information-seeking behaviour of LIS professionals and how this relates to the use of seeking and alerting services. The questions that can be asked are: (I) How do they try to meet their information needs (e.g. bridging the gap)? (2) What knowledge do they need and what do they know that will enable them to use alerting services successfully? (3) What barriers influence their use of alerting services?

The range of topics covered by the different chapters is quite diverse. This makes it a valuable resource for researchers and novice researchers who want an overview of current and alerting services.

The book not only gives a wealth of information on current awareness services both manual and web-based, but also provides detailed accounts of electronic newsletters, discussion lists, article alerting services, weblogs, as well as automated tracking tools. Much has been detailed about the positive aspects of alerting services without neglecting the details of the negative aspects of alerting services and how to deal with them. As seen from the background information provided about each alerting service, one is made to think of the benefits more than the disadvantages of using them. It is hoped that all LIS professionals would be able to relate to the issues discussed concerning alerting services and make greater use of them.

The book will be useful to LIS professionals but to academics and all those interested in keeping abreast with their research. It is very readable, providing valuable information that can be used to benchmark a library, as well as ideas on how to introduce the alerting services to students and staff.

Reviewed by: Dr Daisy Jacobs, Senior Lecturer, Department of Library and Information Science, University of Zululand, South Africa.

Tel.: (035) 9026832

Email: djacobs@pan.uzulu.ac.za 